\title{
Development of chemically modified electrode using cucurbit(6)uril to detect ranitidine hydrochloride in pharmaceutical formulation by voltammetry
}

\begin{abstract}
A new, simple, precise, accurate and selective method for ranitidine hydrochloride ( $\mathrm{RNH})$ quantification was developed based on the electrochemical oxidation of RNH on the pencil graphite electrode (PGE) modified with p-amino benzene sulfonic acid/cucurbit(6) uril (p-ABSA/CB (6)). During analysis, an electrochemical cell was employed with a conventional three-electrode system and $\left(0.1 \mathrm{molL}^{-1}\right)$ potassium chloride $\mathrm{KCl}$ solution as the supporting electrolyte. Under optimal experimental conditions, the peak current response increases linearly with a ranitidine concentration over the range of $2 \times 10^{-4}-1.7 \times 10^{-2} \mathrm{molL}$

${ }^{1}$. The detection limit of the method was estimated to be $1.5746 \times 10^{-4} \mathrm{molL}^{-1}$. To further validate its possible application, the proposed method was successfully used for the determination of RNH in pharmaceutical formulation. The scanning electron microscope was accomplished to investigate the structural behavior of the film that originated on the electrode surface.
\end{abstract}

Keywords: ranitidine hydrochloride (RNH), cucurbiturils, voltammetry
Volume 7 Issue $6-2018$

\author{
Shahd Moutasim Merghani,Abdalla Ahmed \\ Elbashir \\ University of Khartoum, Department of Chemistry, Sudan
}

Correspondence: Abdalla Ahmed Elbashir, University of Khartoum, Faculty of Science, Department of Chemistry, Khartoum I I I I, Sudan, Tel +249566 |43 I43II,

Email aaelbasher@uofk.edu

Received: May 14, 2018| Published: November 14, 2018

\section{Introduction}

Ranitidine hydrochloride (RNH), chemically $\mathrm{N}$-[2-[[[5[(dimethylamino)methyl]-2-furanyl]methyl]thio]ethyl]-N'-methyl-2nitro-1,1'-ethylenediaminehydrochloride (Figure 1), is a histamine $\mathrm{H}_{2}$-receptor antagonist widely used for the short-term treatment of duodenal and gastric ulceration associated Helicobacter pylori infection, gastroesophageal reflux disease and the treatment of photogenic gastrointestinal hypersecretory condition such as the Zollinger-Ellison syndrome. ${ }^{1-4} \mathrm{RNH}$ is metabolized in the liver by N-oxidation, S-oxidation and demethylation, but it is eliminated mainly as unchanged drug. ${ }^{4-6}$<smiles>CNC(C[N+](=O)[O-])NCCSCc1ccc(CN(C)C)o1</smiles>

$\mathrm{H}-\mathrm{Cl}$

Figure I Chemical structure of ranitidine hydrochloride (RNH).

Overview of the literature reveals that the techniques used for $\mathrm{RNH}$ determination in pharmaceutical and biological fluids include high performance liquid chromatography with various type of detectors such as spectrophotometric, ${ }^{7}$ fluorimetric ${ }^{8}$ and mass spectrometry, ${ }^{9}$ capillary electrophoresis, ${ }^{10}$ titrimetry ${ }^{11}$ colorimetry, ${ }^{12,13}$ reflectometry, ${ }^{14}$ flow injection fluorimetry, ${ }^{15}$ polarography, ${ }^{16}$ voltammetry, ${ }^{2-4,17}$ spectrofluorimetry, ${ }^{18}$ near infrared reflectance spectroscopy ${ }^{19}$ and indirect UV-Vis spectrophotometry. ${ }^{20}$ However, some of these methods are complicated and time-consuming; involve the use of large volume of organic solvents ${ }^{7-9}$ and specific reagent ${ }^{20}$ and requirement of expensive instruments..$^{7-9}$

Electrochemical analysis is a suitable method for various secretory-related problems due to its speed, simplicity, sensitivity and selectivity and the use of less expensive components and the possibility of construction of electrochemical sensors from various type of material. ${ }^{4}$ In order to improve the sensitivity and selectivity of these devices the physico-chemical nature of the electrode solution at the interface are changed by adding different chemical species to the electrode surface. ${ }^{2}$ The choice of working electrode plays an important role in electrochemical determination. Solid electrodes are a better option than are the current liquid electrodes. Hence, pencil graphite electrode (PGE) was selected as a working electrode. ${ }^{4}$ Electrochemical methods have been also applied for RNH determination including voltammetry, potentiometry and polarography. Other articles report the utilization of unmodified surfaces for $\mathrm{RNH}$ quantification, but there are few reports about the use of chemically modified electrodes for its determination. To our knowledge, voltammetric determination of RNH at chemically modified electrode has not been reported yet.

Cucurbit(n)urils or $\mathrm{CB}(\mathrm{n}) \mathrm{s}$ are cyclic organic capsules with a pumpkin like shape. ${ }^{21}$ They bear a central hydrophobic cavity delimited by $\mathrm{n}(5-8,10-12)$ carbonyl groups oriented outward forming electron rich portals on both side of the cavity which confers them their host-guest properties. Additionally, they are symmetric, thermally stable, chemically inert and poorly soluble in water, which little variation among the homologues. ${ }^{22}$ Cucurbit (6) uril (CB (6)) is a toroidal molecule obtained by the acid-catalyzed condensation of glycouril and formaldehyde. ${ }^{23-25}$ Charge dipole interaction as well as hydrogen bonding between the protonated amine group of the guest and the carbonyl group at the entrance of CB (6) is responsible for the high affinity of these substrates and allows to the stabilization of inclusion complexes. ${ }^{25,26}$ The unique interaction possibilities offered by these interesting macrocycles make them excellent candidate to be used in chemical sensor development. The incorporation of CB (6) on the electrode surface was expected to increase the selectivity of the electrochemical sensor because of the host-guest recognitions. ${ }^{26,27}$

The work presented here describes the use of a PGE modified with p-amino benzene sulfonic acid/cucurbit (6)uril to study the electrochemical oxidation of RNH and its use in determination of this drug in pharmaceutical formulation using cyclic voltammetry (CV) and differential pulse voltammetry (DPV). The results showed that the 
modified electrode enhanced the oxidation peak of $\mathrm{RNH}$ as compare to the unmodified electrode. The analytical procedure proposed is easy to adopt, rapid, low cost and good reproducible.

\section{Experimental}

\section{Reagents}

Ranitidine hydrochloride was kindly provided from General medicine company (Khartoum, Sudan) and its stock standard solution of $0.1 \mathrm{molL}^{-1}$ was prepared in deionized water. Tablet containing a label claim of $150 \mathrm{mg}$ RNH Julphar (U.A.E) was purchased from a local pharmacy.

Cucurbit (6) uril (CB (6)) was purchased from Sigma-Aldrich (St.Louis, USA), p-amino benzene sulfonic acid (p-ABSA) was purchased from SDFCL, disodium hydrogen phosphate from Labtech chemicals. A $0.1 \mathrm{molL}^{-1} \mathrm{KCl}(\mathrm{pH}=8.0)$ solution was used as the supporting electrolyte. All solutions were purged with nitrogen gas for the removal of dissolved oxygen before starting the experiment. All chemicals used were of analytical grade and deionized water was used throughoutthis work.

\section{Apparatus}

Electrochemical measurements were carried out using a potentiostat-galvanostat $\mu$ Autolab (Echochemie, B.V., Netherlands, NOVA softare) and a conventional three electrode arrangement consisting of PGE modified with p-ABSA/CB (6) as the working electrode ( $\mathrm{PGE}$ type is $\mathrm{HB}=2 \frac{1}{2}$ Faber-Castell gold faber 1222), an $\mathrm{Ag} /$ $\mathrm{AgCl} / \mathrm{KCl}\left(3 \mathrm{molL}^{-1}\right)$ as the reference electrode (Inner filling Metrohm 6.0726.100Ag, $\mathrm{AgCl} / 080^{\circ} \mathrm{C}$, outer filling 01153123) and a platinum wire (Metrohm 6.0301.100pt/-2070 ${ }^{\circ} \mathrm{C} 01250290$ ) as the auxiliary electrode.

Scanning electron microscopy(SEM) was performed with Zeiss Evo LS 10.Germany. pH-meter (PHS-3H) (China) was usedto measure the $\mathrm{pH}$ values.

\section{Methodology}

\section{Preparation of the p-ABSA/methanol/CB (6) solution}

The p-ABSA solution $(2.6 \mu \mathrm{L})$ was transferred to a $1.00 \mathrm{~mL}$ container. A $7.9 \times 10^{-4} \mathrm{molL}^{-1} \mathrm{CB}$ (6) solution was prepared using $0.2 \mathrm{molL}^{-1} \mathrm{NaCl}$ solution and transferred* $(4.4 \mu \mathrm{L})$ to the container were p-ABSA had been placed. The container volume was make upwith methanol**; the final solution was sonicated. ${ }^{*} \mathrm{CB}(6)$ was not completely solubilized underthe experimental conditions. Hence, it was submitted to sonication for 30 seconds before being transferred, to guarantee that the analyses were quantitative. ${ }^{* *}$ The analysis was conducted using either methanol or acetonitrile and no significant differences in terms of solvent evaporation time construction of the CME. Therefore, methanol was used.

Construction of chemically modified electrodes (CMEs) the polished electrode was sonicated in distilled water for about $5 \mathrm{~min}$, to eliminate any impurity that might have remained from the polishing procedure. Then, $2.5 \mu \mathrm{L}$ of the $\mathrm{p}-\mathrm{ABSA} / \mathrm{CB}(6)$ solution described in the above section was added over the electrode surface by dip coating. This process was repeated after solvent gets evaporated.

\section{Voltammetric analysis}

A conventional three-electrode system consisting of a platinum spiral auxiliary electrode, $\mathrm{Ag} / \mathrm{AgCl}$ reference electrode filled with $\left(3 \mathrm{molL}^{-1}\right) \mathrm{KCl}$, and a PGE modified with p-ABSA/CB (6) as working electrode were employed during voltammetry. A $\left(0.1 \mathrm{molL}^{-1}\right) \mathrm{KCl}$ solution was added to the electrochemical cell. Oxygen was removed from the solutions by applying a nitrogen flow for approximately 1 $\min$.

\section{Results and discussion \\ PGE modified with p-ABSA/CB (6) characterization}

SEM image of the PGE modified with p-ABSA/CB (6) sample used for electrode modification was shown in Figure 2. A few microliters of aqueous suspensions of these materials were deposited on a freshly polished PGE electrode. The characteristic graphene feature was observed, the sample being constituted by sheets of about $1 \mu \mathrm{m}$ size. The fact that the presence of CB (6) cannot be inferred from the SEM image is compatible with these organic capsules being well dispersed on the graphene layer.

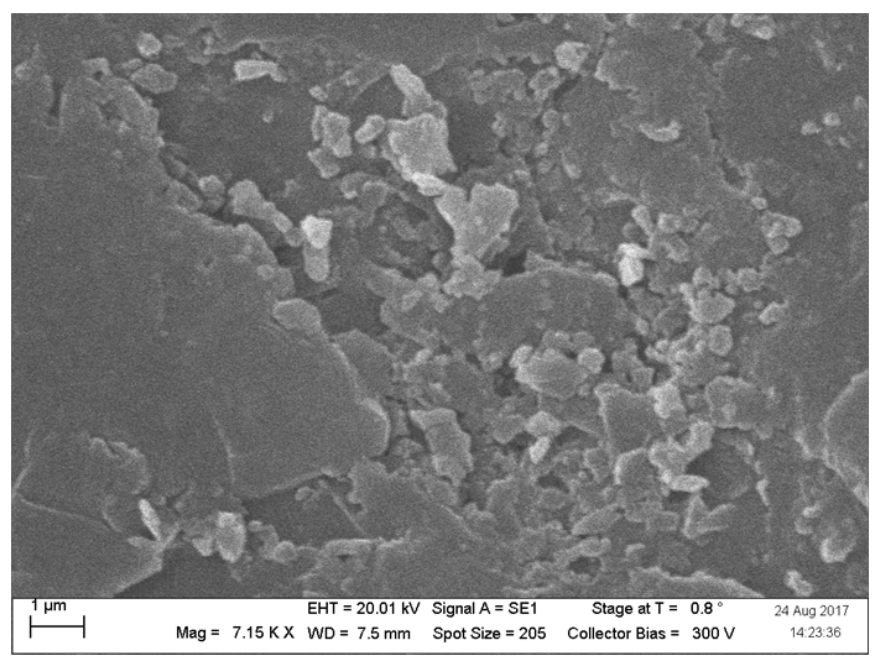

Figure 2 Scanning electron microscopy SEM of PGE modified with p-ABSA/ $\mathrm{CB}(6)$.

\section{Electrochemical characterization}

Cyclic voltammograms of unmodified and modified electrodes are shown in Figure 3. These voltammograms are taken with $5 \mathrm{mmolL}^{-1}$ $\mathrm{K}_{3}\left[\mathrm{Fe}(\mathrm{CN})_{6}\right] / 0.1 \mathrm{molL}^{-1} \mathrm{KCl}$ system. In the case of the modified electrode redox couple $\left[\mathrm{Fe}(\mathrm{CN})_{6}\right]^{-3} /\left[\mathrm{Fe}(\mathrm{CN})_{6}\right]^{-4}$ gave a well-defined oxidation and reduction peaks during the forward and reverse scan at potential range of -0.4 to $0.8 \mathrm{~V}$ at scan rate $100 \mathrm{mVs}^{-1}$. Peak separation value indicated a quasi-reversible electrode behavior.

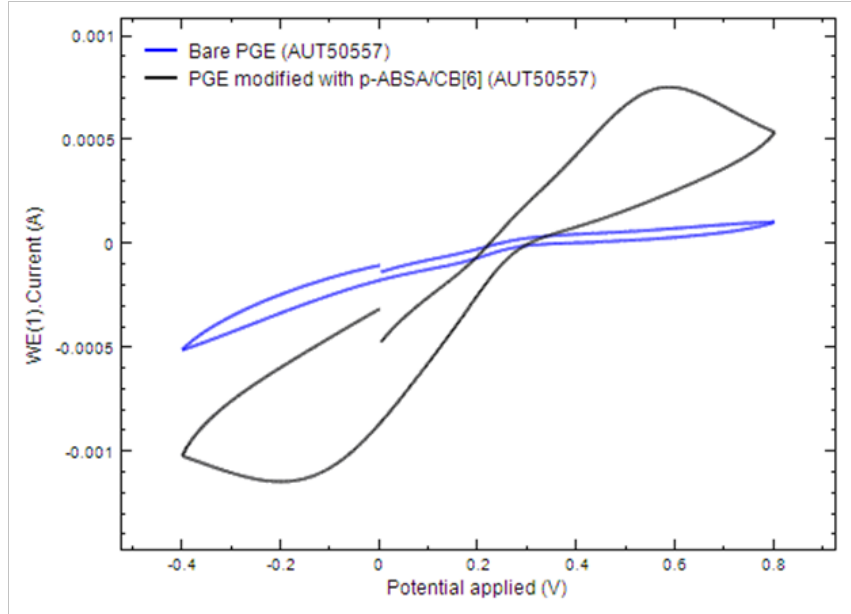

Figure 3 Cyclic voltammograms of $5 \mathrm{mmolL}^{-1} \mathrm{~K} / \mathrm{Fe}(\mathrm{CN})_{6}$ and $0.1 \mathrm{molL}^{-1} \mathrm{KCl}$ at bare PGE and PGE modified with $\mathrm{P}-\mathrm{ABSA} / \mathrm{CB}(6)$ at scan rate $100 \mathrm{mVs}^{-1}$. 
The relation between redox peak currents and square root of scan rate helped to calculate the electrochemical surface area by using following Randles Sevcik equation no. 1:

$$
\mathrm{I}_{\mathrm{p}}=2.65 \times 10^{5} \mathrm{n}^{3 / 2} \mathrm{AD}^{1 / 2} \mathrm{C}^{*} \mathrm{v}^{1 / 2}(1)
$$

In the equation no. $1, \mathrm{n}$ denotes the number of electrons that involve in the redox reaction, $\mathrm{v}$ represent the scan rate of the potential perturbation $\left(\mathrm{v} \mathrm{s}^{-1}\right)$, A shows the area of the electrode $\left(\mathrm{cm}^{2}\right)$, D denotes the diffusion coefficient of the molecules in the solution $\left(\mathrm{cm}^{2} \mathrm{~s}^{-1}\right)$, $\mathrm{C}^{*}$ indicates the concentration of the probe molecule in the bulk solution $\left(\mathrm{molL}^{-1}\right)$, and $\mathrm{I}_{\mathrm{p}}$ defines the peak current of the redox couple. According to the equation, the effective surface area (A) can be calculated by using the value of $\mathrm{I}_{\mathrm{p}} / \mathrm{v}^{1 / 2}$, while maintaining the constant values of $\mathrm{D}, \mathrm{n}(\mathrm{n}=1)$, and $\mathrm{C}^{*}\left(5 \mathrm{mmolL}^{-1}\right)$. The diffusion constant value at $25^{\circ} \mathrm{C}\left(\mathrm{D}=7.6 \times 10^{-5} \mathrm{~cm}^{2} \mathrm{~s}^{-1}\right)$ was determined using the previously published data. ${ }^{28}$ A linear increase in the $I_{p}$ was observed as the square root of the potential scan rate $\left(\mathrm{v}^{1 / 2}\right)$ increased, which indicates the reversibility of the reaction occurring on the modified electrode. The electroactive surface area of the bare PGE cannot be calculated because of the disappearance of the peak while the electroactive area of the PGE modified with $\mathrm{p}-\mathrm{ABSA} / \mathrm{CB}(6)$ was calculated as $1.6 \times 10^{-5}$ $\mathrm{cm}^{2}$. Thus, the sensor PGE modified with p-ABSA/CB (6) became more sensitivity to RNH.

\section{Electrochemical sensors developed using cucurbiturils}

The CB (n) $(n=5-8)$ have several members, which present a cavity diameter of $0.44,0.58,0.73$ and 0.88 for $n=5,6,7$ and 8 , respectively. Their general inclusion properties are high affinity and highly selective, constrictive binding interactions with lots of specific guest species, driven by a combination of ion-dipole interactions, hydrogen bonds and hydrophobic effect. ${ }^{21}$ It is possible to immobilize cucurbiturils over electrodes. CB (n) act as chemical mediators, giving rise to a promising class of chemically modified electrodes (CMEs). CMEs with $\mathrm{CBs}$ can be prepared in essentially two ways: $\mathrm{CB}$ adsorption or $\mathrm{CB}$ immobilization on a polymeric matrix. ${ }^{22}$ The presence of $\mathrm{p}$-ABSA accelerate the electron transfer.

The chemical structure of RNH bears oxygen atom close to the aromatic ring (furan). It is very improbable that it could interact with CB (6) from this side. The electron density is too high, and the aromatic ring would hardly fit the cavity of the macrocycle. The other side of the molecule, however, could perfectly enter the cavity, especially if the nitrogen atom is protonated.

\section{Electrochemical behavior of ranitidine hydrochloride}

The electrochemical behavior of RNH was examined by cyclic voltammetry $(\mathrm{CV})$. As can be seen, no redox peakswere observed at bare PGE (Figure 4a) and PGE modified with p-ABSA/CB (6) (Figure $4 \mathrm{c})$ in the blank $\mathrm{KCl}$, indicating that graphene in the PGE and $\mathrm{CB}(6)$ are nonelectroactive in the selected potential window. When $1.0 \times 10^{-}$ ${ }^{2} \mathrm{molL}^{-1} \mathrm{RNH}$ was added into $\mathrm{KCl}$, no oxidation peak was observed at bare PGE (Figure 4b). However, under the same conditions, a sensitive, well-defined oxidation peak of $\mathrm{RNH}$ was obtained at PGE modified with p-ABSA/CB (6) (Figure 4d). The remarkable peak current enhancement is undoubtedly attributed to the unusual structure and properties of $\mathrm{CB}$ such as high aspect ratio and excellent electrocatalytic activity. As can be observed in (Figure 4d), during the positive scan an anodic current peak is obtained in the analyzed solution. However, there is no reduction peak during the negative scan, indicating that the electrochemical reaction of RNH was totally irreversible. ${ }^{3}$ The anodic peak can be attributed to the amino group oxidation, as the potential value corresponds to the potential range for the oxidation of different anilines $(0.8-1.2 \mathrm{~V}$ depending on the degree of substitution). ${ }^{29}$ The RNH oxidation peak observed here is consistent with literature data, with minimal deviation. The latter may result from the fact that the experiment was conducted with slightly different conditions. The anodic peak appeared at $1.4 \mathrm{~V}$.

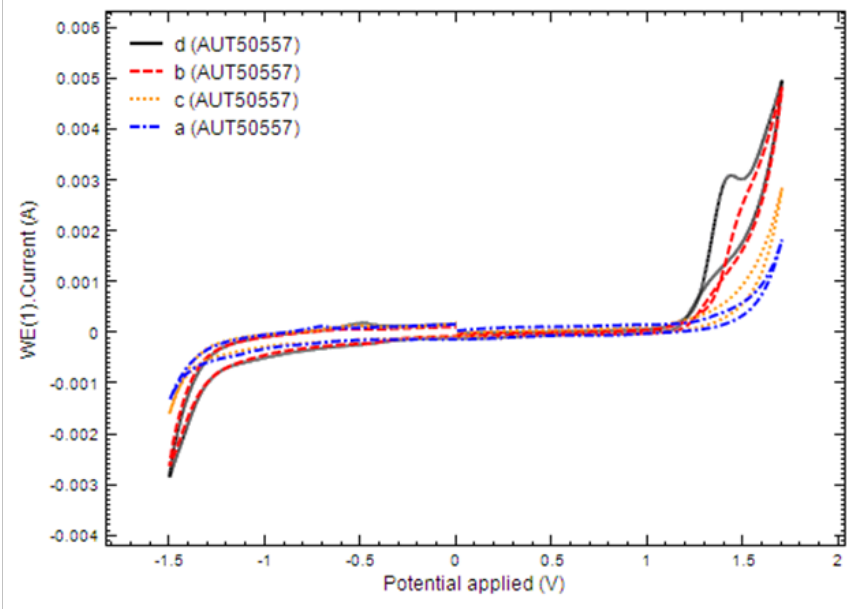

Figure 4 Cyclic voltammograms of bare PGE $(a, b)$ and PGE modified with $\mathrm{p}-\mathrm{ABSA} / \mathrm{CB}(6)(\mathrm{c}, \mathrm{d})$ when placed in $0.1 \mathrm{~mol} \mathrm{~L}^{-1} \mathrm{KCl}(\mathrm{pH}=8.0)$ in the presence $(b, d)$ and absence $(a, c)$ of $1 \times 10^{-2} \mathrm{molL}^{-1} \mathrm{RNH}$. Scan rate $100 \mathrm{mVs}^{-1}$.

\section{Optimization conditions}

Effect of pH: The voltammetric response of a PGE modified with p-ABSA/CB (6) was evaluated over a $\mathrm{pH}$ range between 2.0 to 8.5 in the solution containing $1.0 \times 10^{-2} \mathrm{molL}^{-1} \mathrm{RNH}$. An anodic current peak was obtained during the positive scan. According to Figure 5, we can observe an increasing in the anodic peak current in agreement to $\mathrm{pH}$ until a maximum value of 8.0 , after this value, the magnitude of current decreases. Thus, a $\mathrm{pH}$ value of 8.0 was chosen for further studies. That behavior can be explained by looking for the $\mathrm{pK}_{\mathrm{a}}$ value. The acid-base equilibrium of the ranitidine occurs due to the formation of an anionic species stabilized by resonance with value of $\mathrm{pK}_{\mathrm{a}}=2.7$, the acidity of the $=\mathrm{CH}-$ group is increased by the presence of the nitro group, and the $=\mathrm{C}(\mathrm{NHR})$, group, resemble the $\mathrm{pK}$ of the dinitromethane $\left(\mathrm{pK}_{\mathrm{a}}=3.6\right)$. At $\mathrm{pH}>\mathrm{pK}_{\mathrm{a}}$, a carbanion is also stabilized owing to the presence of two nitro groups, and the carbanion nitronate predominated in the solution and protonation on the carbanion occurs slowly. ${ }^{6}$ The anionic species present ionic mobility higher than the protonated species coming more easily to the electrode surface.

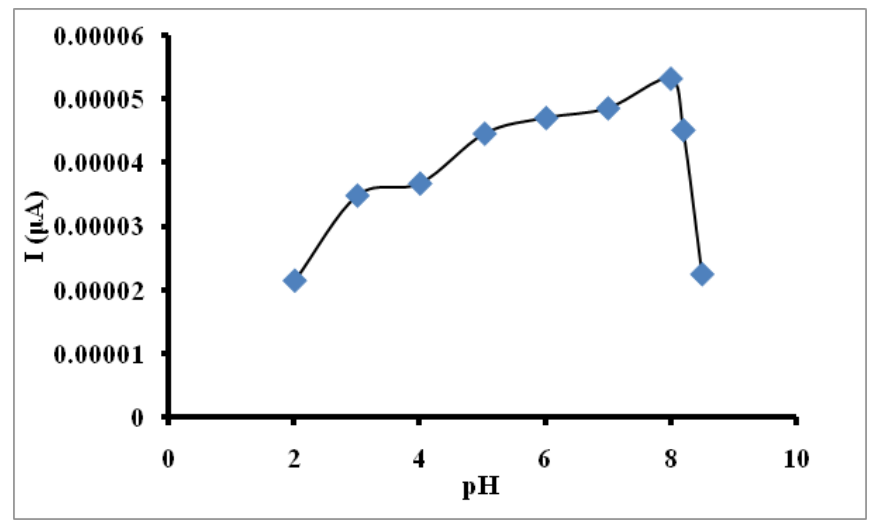

Figure 5 Effect of $\mathrm{pH}$ on the voltammetric response for the PGE modified with $\mathrm{p}-\mathrm{ABSA} / \mathrm{CB}(6)$ in the presence of $1 \times 10^{-2} \mathrm{molL}^{-1} \mathrm{RNH}$ in $0.1 \mathrm{molL}^{-1} \mathrm{KCl}$ at scan rate $100 \mathrm{mVs}^{-1}$. 
Effect of scan rate: The effect of scan rate on the peak current of RNH was investigated by cyclic voltammetry as shown in Figure 6. It was found that the peak current was proportional to the square root of scan rate over the range from 10 to $100 \mathrm{mVs}^{-1}$, providing further evidence that the electrode reaction of RNH at PGE modified with p-ABSA/CB (6) is diffusion controlled. ${ }^{3}$ Figure 7 shows a straight line plot of peak current vs. square root of scan rate. From the sharp shape of the voltammograms, an adsorption process seems likely. However, the slope $\log I_{p}$ vs. $\log$ v was 0.5846 as shown in Figure 8 , which leads to the conclusion that the process follows diffusion control at this $\mathrm{pH}$ value. The expected theoretical value for this slope is 0.5 for diffusion control and 1 for adsorption control..$^{30}$ From these results, a scan rate of $100 \mathrm{mVs}^{-1}$ was chosen for further studies due to the best peak definition in the presented voltammograms. The peak potentials shifted positively which implied the irreversible nature of the electrode reaction processes.

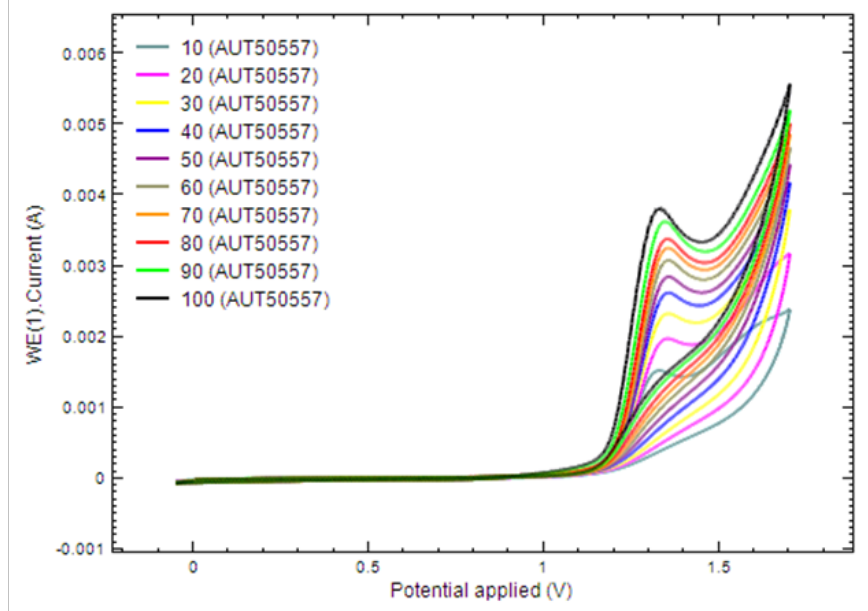

Figure 6 Cyclic voltammograms of $1 \times 10^{-2} \mathrm{molL}^{-1} \mathrm{RNH}$ at $\mathrm{pH} 8.0$ on the PGE modified with $\mathrm{p}-\mathrm{ABSA} / \mathrm{CB}(6)$ at several scan rates $10,20,30,40,50,60,70$, 80,90 and $100 \mathrm{mVs}^{-1}$.

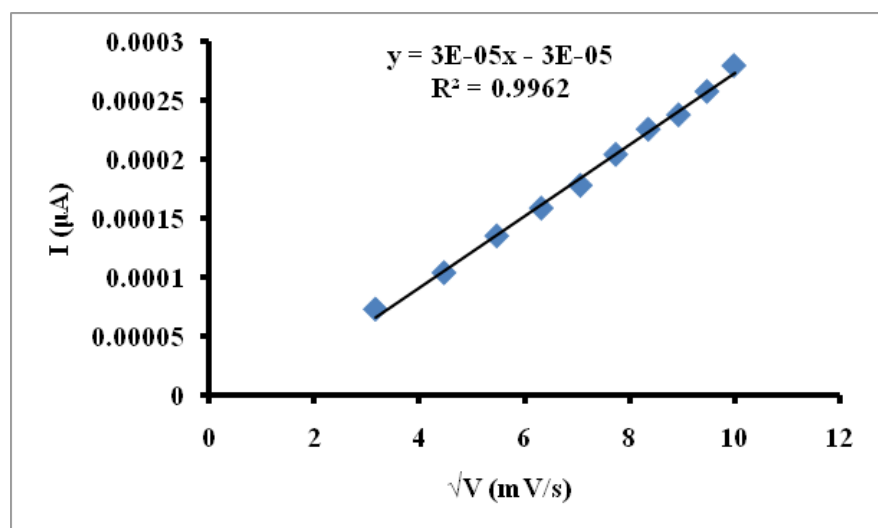

Figure 7 Plot of peak current $(1 / \mu \mathrm{A}) \mathrm{vs}$. square root of scan rate $ل_{\mathrm{v}}\left(\mathrm{mVs}^{-1}\right)$.

Effect of accumulation time: Accumulation prior to voltammetric measurements could influence the electro oxidation of RNH at PGE modified with p-ABSA/CB (6). However, the accumulation time had a remarkable effect on peak current. The maximum peak current with the accumulation time of $5 \mathrm{sec}$., when the accumulation time exceeded $5 \mathrm{sec}$. the current decreases (data not shown), suggesting that the accumulation process of RNH had achieved its saturation on graphene film. Therefore, $5 \mathrm{sec}$. accumulation time was used to improve sensitivity of the method and shorten the time consumption.

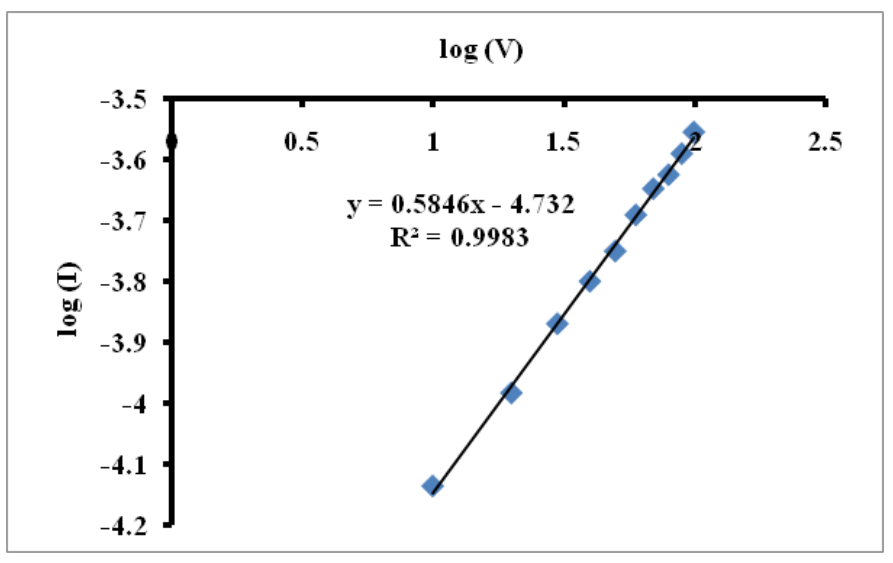

Figure 8 Plot of log. Peak current (I) vs. log. scan rate (v).

Validation: The present method was validated by determining several parameters recommended by ICH guidelines: ${ }^{31,32}$ linearity, precision, accuracy, robustness and selectivity.

Linearity: Under the optimized experimental conditions the differential pulse voltammograms of $\mathrm{RNH}$ with different concentrations at PGE modified with p-ABSA/CB (6) were recorded. The peak current increased linearly with incremental concentration of $\mathrm{RNH}$ in the range from $2 \times 10^{-4}$ to $1.7 \times 10^{-2} \mathrm{molL}^{-1}$, as shown in Figure 9 , giving a regression equation no. 2 , with correlation coefficient $\mathrm{R}^{2}=0.9998$.

$\mathrm{Y}=0.0008 \mathrm{x}+3 \times 10^{-7}$ Equation no. 2

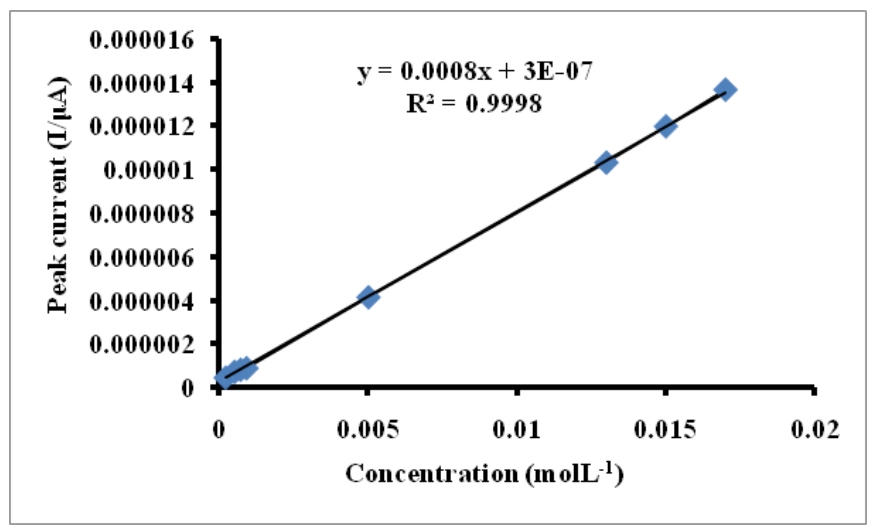

Figure 9 Calibration plot of peak current $(1 / \mu \mathrm{A})$ vs. concentration of $\mathrm{RNH}$ $\left(\mathrm{molL}^{-1}\right)$.

\section{LOD and LOQ}

The LOD was measured as the lowest amount of the analyte that may be detected to produce a response which is significant different from that of a blank. Limit of detection was approved by calculations based on the standard deviation of the response $(\delta)$ and the slope (S)of the calibration curve at the levels approaching the limits according to equation $\mathrm{LOD}=3.3(\delta / \mathrm{S})$. The $\mathrm{LOQ}$ was measured at the lowest amount of analyte that can be reproducibly quantified above the baseline noise and can be calculated according to the equation $\mathrm{LOQ}=10(\delta / \mathrm{S})$. The values were shown in Table 1.

\section{Precision}

The precision of the assay was investigated with respect to both repeatability and reproducibility. Repeatability was determined by 
measuring three replicate samples of each of the $1.3 \times 10^{-2}, 1.5 \times 10^{-2}$, and $1.7 \times 10^{-2} \mathrm{molL}^{-1}$ standards where the mean concentrations were found to be $1.294 \times 10^{-2}, 1.507 \times 10^{-2}$ and $1.7865 \times 10^{-2} \mathrm{molL}^{-1}$ with associated R.S.D of $0.07656,0.12323$ and 0.20078 respectively, indicating that the PGE modified with p-ABSA/CB (6) presented good repeatability. Inter-day precision was assessed by measuring the same three concentrations over 5 consecutive days resulting in mean concentrations of ranitidine of $1.2811 \times 10^{-2}, 1.5385 \times 10^{-2}$ and $1.7098 \times 10^{-2} \mathrm{molL}^{-1}$ with associated R.S.D of $0.4180,0.36058$ and 0.0499 respectively, indicating good reproducibility.

Table I Parameter for RNH voltammetric method

\begin{tabular}{ll}
\hline Parameter & Value \\
\hline Linear range $\left(\mathrm{molL}^{-1}\right)$ & $2 \times 10^{-4}-1.7 \times 10^{-2}$ \\
Intercept $\pm \mathrm{SD}$ & $3 \times 10^{-7} \pm 3.81725 \times 10^{-8}$ \\
Slope & $8 \times 10^{-4}$ \\
Standard deviation & $5.65589 \times 10^{-6}$ \\
Correlation coefficient $\left(\mathrm{R}^{2}\right)$ & 0.9998 \\
Practical limit of detection $(\mathrm{LOD})\left(\mathrm{molL}^{-1}\right)$ & $1 \times 10^{-4}$ \\
Limit of detection $(\mathrm{LOD})\left(\mathrm{molL}^{-1}\right)$ & $1.5746 \times 10^{-4}$ \\
Limit of quantification $(\mathrm{LOQ})\left(\mathrm{molL}^{-1}\right)$ & $4.7716 \times 10^{-4}$ \\
\hline
\end{tabular}

\section{Accuracy}

Accuracy was determined by analyzing a fixed amount of the pure drug (the standard) and the drug in the dosage form and the percentages of recovery at three levels of concentration were calculated. Recovery data obtained within the 95.99-102.34\% range as shown in Table 2.

Table 2 Accuracy of the voltammetric method for RNH determination

\begin{tabular}{llll}
\hline $\begin{array}{l}\text { Standard } \\
\left(\mathrm{molL}^{-1}\right)\end{array}$ & $\begin{array}{l}\text { Sample } \\
\left(\mathrm{molL}^{-1}\right)\end{array}$ & Found $\left(\mathrm{molL}^{-1}\right)$ & Recovery\% \pm R.S.D \\
\hline $\mathrm{I} \times 10^{-4}$ & $1.29 \times 10^{-2}$ & $1.3129 \times 10^{-2}$ & $100.99 \% \pm 0.7133$ \\
$1 \times 10^{-4}$ & $1.49 \times 10^{-2}$ & $1.5351 \times 10^{-2}$ & $102.34 \% \pm 0.2844$ \\
$1 \times 10^{-4}$ & $1.69 \times 10^{-2}$ & $1.6318 \times 10^{-2}$ & $95.99 \% \pm 0.1177$ \\
\hline
\end{tabular}

\section{Robustness}

The robustness of the method was investigated under a variety of conditions such as small changes in the $\mathrm{pH}$, scan rate and accumulation time. As can be seen in Table 3, the percent recoveries of RNH were good. Under most conditions no significant change when the critical parameters were modified.

Table 3 Influence of changes in experimental conditions on the performance of voltammetric method

\begin{tabular}{lll}
\hline Parameter & Modification & Recovery\% \pm R.S.D* \\
\hline & 7.8 & $100.41 \% \pm 0.2002$ \\
& 8.0 & $100.9 \% \pm 0.1471$ \\
$\mathrm{pH}$ & 8.2 & $99.42 \% \pm 0.206 \mathrm{I}$ \\
& 98 & $96.38 \% \pm 0.0109$ \\
Scan rate $\left(\mathrm{mVs}^{-1}\right)$ & 100 & $100.56 \% \pm 0.1059$ \\
& 3 & $97.81 \% \pm 0.1261$ \\
Accumulation time & 5 & $100.9 \% \pm 0.1472$ \\
$(\mathrm{sec})$. & 7 & $96.12 \% \pm 0.2394$ \\
\end{tabular}

*Values are mean of 3 determinations

\section{Selectivity}

In order to evaluate the effect of several species frequently found with RNH in pharmaceutical formulation on the electrode response, a study involving these compounds was performed. The selectivity of the proposed method was evaluated by voltammetric measurements performed in $0.1 \mathrm{molL}^{-1} \mathrm{KCl}(\mathrm{pH}=8.0)$ solution containing $1.0 \times 10^{-2}$ molL $^{-1}$ of RNH spiked with different interferents (sucrose, lactose, starch, magnesium stearate and L-Ascorbic acid). The responses were not different from that obtained in the calibration. Hence, the determination of ranitidine in this formulation is considered to be free from formulation components.

\section{Analysis of pharmaceutical samples}

The method developed in the present study was applied for the determination of RNH in tablet from Julphar (U.A.E.). The result showed a percent recovery of $99.73 \%$ with a R.S.D of 0.140298 , which indicate that the proposed method is accurate.

\section{Comparison of the sensitivity of the proposed method and other previously reported method}

Different approaches have been reported for RNH quantification. Some of them correspond to batch techniques, mainly flow injection amperometric method using spectrophotometric detector having detection limit comparable with the proposed method. The detection limit of the proposed is in the near range as those of the reference method, ${ }^{33}$ which was found to be $1.57 \times 10^{-4} \mathrm{molL}^{-1}, 1 \times 10^{-5} \mathrm{molL}^{-1}$, respectively. Therefore, it can be concluded that the proposed method is in agreement with the reference method.

\section{Conclusion}

In this study, RNH was irreversibly anodically oxidized on the PGE modified with p-ABSA/CB (6) in the potential located around $1.4 \mathrm{~V}$, which is consistent with the literature report. The irreversible anodic oxidation indicates diffusion-controlled mechanism. The enhancement in the oxidation current in the modified electrode might be attributed to the presence of the CB (6). The proposed method is fast, precise, convenient to be applied for the quantification of RNH in pharmaceutical formulation.

\section{Acknowledgements}

The authors gratefully acknowledge Dr. Manal Siyam for analysis sample by SEM in Naturkundi Museum laboratories-Berlin-Germany.

\section{Conflict of interest}

The author declares that there is no conflict of interest.

\section{References}

1. Maslarska V. Determination of ranitidine hydrochloride in pharmaceutical preparations by direct potentiometry. J Pharm Pharm Sci. 2014;6(1):538-540.

2. Raymundo-Pereira PA., Teixeira MFS., et al. Electrochemical sensor for ranitidine determination based on carbon paste electrode modified with oxovanadium (IV) salen complex. Mater Sci Eng C. 2013;33(7):40814085 .

3. $\mathrm{X}_{\mathrm{I}} \cdot \mathrm{X}_{\mathrm{IA}}$, Ming L. Electrochemical determination of ranitidine hydrochloride in pharmaceutical formulations and biological fluids at graphene modified electrode. Asian J Chem. 2013;25(10):5315-5318.

4. Vediappan K, Lee CW. Electrochemical approaches for the determination of ranitidine drug mechanism. Curr Appl Phys. 2011;11:995-1000. 
5. Olvera-Vargas H, Oturan N, Brillas E, et al. Electrochemical advanced oxidation for cold incineration of the pharmaceutical ranitidine: Mineralization pathway and toxicity evolution. Chemosphere. 2014;117:644-651.

6. Richter P., Toral MI., Muñoz-Vargas F. Polarographic behavior and determination of ranitidine in pharmaceutical formulations and urine. Analyst. 1994;119:1371-1374.

7. Arayne MS., Sultana N., et al. Simultaneous determination of metformin, cimetidine, famotidine, and ranitidine in human serum and dosage formulations using HPLC with UV detection. J Chromatogr Sci. 2010;48(9):721-725

8. Khedr A. Sensitive determination in rabbit plasma by HPLC with fluorescence detection. J Chromatogr B Anal Technol Biomed Life Sci. 2008;862(1-2):175-180.

9. Van Nuijs ALN, Tarcomnicu I, Simons W, et al. Optimization and validation of a hydrophilic interaction liquid chromatographytandem mass spectrometry method for the determination of 13 topprescribed pharmaceuticals in influent wastewater. Anal Bioanal Chem. 2010;398(5):2211-2222.

10. Martinez-G-omez MA, Carril-Avilés MM, Sagrado S, et al. Characterization of antihistamine-human serum protein interactions by capillary electrophoresis. J Chromatogr A. 2007;1147(2):261-269.

11. Basavaiah K, Nagegowda P. Determination of ranitidine hydrochloride in pharmaceutical preparations by titrimetry and visible spectrophotometry using bromate and acid dyes. Faramco. 2004;59(2):147-153.

12. Darwish IA., Hussein SA., et al. Spectrophotometric determination of $\mathrm{H}_{2}$-receptor antagonists via their oxidation with cerium (IV). Spectrochim Acta A. 2008;69(1):33-40.

13. Amin AS, Ahmed IS, Dessouki HA, et al. Utility of oxidation-reduction reaction for the determination of ranitidine hydrochloride in pure forms and in the presence of its oxidative degradates. Spectrochim Acta A. 2003;59(4):695-703

14. Lima LS, Weinert PL, Lemos SC, et al. An environmentally friendly reflectometric method for ranitidine determination in pharmaceuticals and human urine. Spectrochim Acta A. 2009;71(5):1999-2004.

15. Lopez-Erroz C, Vinas P, Natalia Campillo, et al. Flow injectionfluorimetric method for the determination of ranitidine in pharmaceutical preparations using o-phthaladehyde. Analyst. 1996;121:1043-1046.

16. Richter P, Toral MI, Muñoz-Vargas F. Polarographic behavior and determination of ranitidine in pharmaceutical formulations and urine. Analyst. 1994;119:1371-1374.

17. Norouzi P, Ganjali MR, Daneshgar P. A novel method for fast determination of ranitidine in its pharmaceutical formulations by fast continuous cyclic voltammetry. J Pharmacol Toxicol Methods. 2007;55(3):289-296

18. Ahmad AKS, Abdel Kawy M, Nebsen M. Spectrophotometric and spectrofluorimetric determination of famotidine and ranitidine using 1, 4-benzoquinone reagent. Anal Lett. 1999;32(7):1403-1419.
19. Rosa SS, Barata PA, Martins JM, et al. Development and validation of a method for active drug identification and content determination of ranitidine in pharmaceutical products using near-infrared reflectance spectroscopy: A parametric release approach. Talanta. 2008;75(3):725733

20. Darwish IA, Hussein SA, Mahmoud AM, et al. A sensitive spectrophotometric method for the determination of $\mathrm{H} 2$ receptor antagonists by mean of $\mathrm{N}$-bromosuccinimide and p-aminophenol. Acta Pharm. 2008;58(1):87-97.

21. Lv Y, Tao C, Huang J, et al. Self-assembly of cucurbit(7)uril on the surface of graphene/gold modified electrode: A novel electrochemical sensing platform. Nanomater Nanotechno. 2016;6:1-7.

22. Tadini MC, Balbino MA, Cristina IE, et al. Developing electrodes chemically modified with cucurbit(6)uril to detect 3,4 methylenedioxymethamphetamine (MDMA) by voltammetry. Electrochim Acta. 2014;121:188-193.

23. Domínguez CSH, Hernández P. Use of graphene and cucurbit(7)uril electrodes for the determination of amantadine in biological fluids. Am J Analyt Chem. 2015;6:623-630.

24. Correia HD, Demets GJ. Cucurbit(6)uril/PVC-based semipermeable membranes as electrode modifiers for electrochemical investigation of insoluble substrates. Electrochem Commun. 2009;11(10):1928-1931.

25. Lee JW, Samal S, Selvapalam N, et al. Cucurbituril homologues and derivatives: New opportunities in supramolecular chemistry. Acc Chem Res. 2003;36(8):621-630.

26. Buaki-Sogo M, Pozo M, Hernandez P, et al. Graphene in combination with cucurbit(n)urils as electrode modifiers for electranalytical biomolecules sensing. Talanta. 2012;101:135-140.

27. Elbashir AA, Aboul-Enein HY. Supramolecular analytical application of cucurbit(n)urils using flurescence spectroscopy. Crit Rev Anal Chem. 2015;45(1):52-61.

28. Zaib M, Athar MM. Electrochemical evaluation of phanerocheaete chrysosporium based carbon paste electrode with potassium ferricyanide redox system. Int J Electrochem Sci. 2015;10:6690-6702.

29. Pfaffen V, Ortiz PI. Alternative method with amperometric detection for the determination of ranitidine. Ind Eng Chem Res. 2010;49:4026-4030.

30. Malagutti AR, Mazo LH. Determination of ranitidine in drugs using a mercury coated platinum ultramicroelectrode and hanging mercury dropping electrode. J Braz Chem Soc. 2003;14(2):274-280.

31. Definition and terminology. ICH Q2A. Guidelines on validation of analytical procedure. Federal Register. 1995;60:11260.

32. Methodology. ICH Q2B. Guidelines on validation of analytical procedure. Federal Register. 1996;60:27464.

33. Perez-Ruiz T, Martinez-Lozano C, Tomas V, et al. Flow-injection extraction spectrophotometric method for the determination of ranitidine in pharmaceutical preparations. J Pharm Biomed Anal. 2001;26(4):609615 . 